\title{
Effects of Microplastics on Immune Responses of the Yellow Catfish Pelteobagrus fulvidraco Under Hypoxia
}

\begin{abstract}
Li'ang $\mathrm{Li}^{1,2,3+}$, Ran $\mathrm{Xu}^{1,2,3+}$, Lingfeng Jiang ${ }^{1,3}$, Elvis Genbo $X \mathrm{u}^{4}$, Man Wang ${ }^{2,5,6}$, Jie Wang ${ }^{2,5,6}$, Bo $\mathrm{Li}^{7}$, Menghong $\mathrm{Hu}^{1,3}$, Lei Zhang ${ }^{2,5,6 *}$ and Youji Wang ${ }^{1,3 *}$

1 International Research Center for Marine Biosciences at Shanghai Ocean University, Ministry of Science and Technology, Shanghai Ocean University, Shanghai, China, ${ }^{2}$ Huai'an Research Centre, Institute of Hydrobiology, Chinese Academy of Sciences, Huai'an, China, ${ }^{3}$ Key Laboratory of Exploration and Utilization of Aquatic Genetic Resources, Ministry of Education, Shanghai Ocean University, Shanghai, China, ${ }^{4}$ Department of Biology, University of Southern Denmark, Odense, Denmark, ${ }^{5}$ The Key Laboratory of Aquatic Biodiversity and Conservation of Chinese Academy of Sciences, Institute of Hydrobiology, Chinese Academy of Sciences, Wuhan, China, ${ }^{6}$ University of Chinese Academy of Sciences, Beijing, China, ${ }^{7}$ Fisheries Research Institute, Wuhan Academy of Agricultural Sciences, Wuhan, China
\end{abstract}

OPEN ACCESS

Edited by:

Jianmin Zhao,

Yantai Institute of Coastal Zone Research, Chinese Academy of

Sciences (CAS), China

Reviewed by:

Zhigang Shen,

Huazhong Agricultural

University, China

Zhihua Feng,

Jiangsu Ocean Universiity, China

*Correspondence:

Lei Zhang

zhanglei@ihb.ac.cn

Youji Wang

Youjiwang2@gmail.com

tThese authors have contributed equally to this work

Specialty section: This article was submitted to

Aquatic Physiology,

a section of the journal

Frontiers in Physiology

Received: 05 August 2021

Accepted: 23 August 2021

Published: 21 September 2021

Citation:

Li L, Xu R, Jiang L, XU EG, Wang $M$,

Wang J, Li B, Hu M, Zhang L and

Wang Y (2021) Effects of Microplastics on Immune Responses of the Yellow Catfish Pelteobagrus fulvidraco Under

Hypoxia. Front. Physiol. 12:753999 doi: 10.3389/fphys.2021.753999
Compared with marine organisms, research on microplastics (MPs) in freshwater organisms is still less although MPs have been widely found in the freshwater ecosystem. Hypoxia is a ubiquitous issue in freshwater aquaculture, and under such scenarios, the toxic effects of MPs on typical aquaculture fish need to be clarified. In this study, we studied the effects of MPs (polystyrene) on specific growth rate (SGR), hypoxia-inducible factor- $1 \alpha(\mathrm{HIF}-1 \alpha)$, tumor necrosis factor- $\alpha(\mathrm{TNF}-\alpha)$, interleukin-8 (IL-8), and interferon (IFN) in the yellow catfish (Pelteobagrus fulvidraco) under hypoxic conditions. After 15 days of exposure, the SGR was not affected by MPs or hypoxia. MPs significantly increased the expressions of HIF- $1 \alpha$ and TNF- $\alpha$ but inhibited the expression of IFN at high concentration MPs under normoxia. However, hypoxia significantly inhibited the expression of IL-8 and TNF- $\alpha$ under high MP concentration and low MP concentration, respectively. In addition, MPs had significant concentration-dependent inhibitory effects on IFN under hypoxia. Surprisingly, a positive correction between HIF-1 $\alpha$ and TNF- $\alpha$ was found in fish. Although hypoxia might alleviate the effects of MPs with low concentrations, the interaction of hypoxia and MPs aggravated the negative effects of MPs on immune factors at high concentration MPs. This study provided new insight into the complex effects of hypoxia and MPs on aquatic organisms, and future studies should focus on the cellular pathways of immune cells in fish. Given that MPs could induce the immune response in fish, considerations should be paid to the impacts of MPs on freshwater aquaculture, and hypoxia should be taken into consideration when evaluating the effects of MPs.

Keywords: microplastics, hypoxia, Pelteobagrus fulvidraco, immune response, specific growth rate

\section{INTRODUCTION}

Microplastics (MPs, $<5 \mathrm{~mm}$ in size) mainly come from the daily life of people or from the aging, weathering, and broken of the large plastic pieces (Cole et al., 2011). Due to their small volume, MPs are difficult to remove by sewage treatment completely (Hamidian et al., 2021), which make them able to flow into inland rivers and eventually into marine ecosystems (Wang et al., 2021a). In 
recent years, many studies have been made on the occurrence of MPs in the environment and their effects on marine organisms, including physical damage, behavior change, tissue lesions, oxidative stress, and gene damage (Huang W. et al., 2021). MPs can also be used as a carrier for some pollutants in the environment and carry the pollutants into the body when organisms ingest MPs, which may cause more serious damages to organisms (Gu et al., 2020).

With the increasing discoveries of MPs in rivers and lakes, MPs have been increasingly viewed as a serious health concern to freshwater ecosystems (Shang et al., 2020). China is a major country in traditional aquaculture (Su et al., 2020), and freshwater aquaculture products account for more than half of the total production in 2020 (Fisheries Administration Ministry of Agriculture Rural Affairs, 2021). In recent years, MPs have been found in major rivers and lakes in China such as Yangtze River, Yellow River, Pearl River, Poyang Lake, Dongting Lake, and Taihu Lake (Fu and Wang, 2019). Especially in Taihu Lake, the concentration of MPs has reached an astonishing 25,800 items $/ \mathrm{m}^{3}$ (Su et al., 2016), which even greatly exceeds the Yellow Sea $\left(0.33\right.$ items $\left./ \mathrm{m}^{3}\right)$ and South China Sea $(2,569$ items $/ \mathrm{m}^{3}$ ) (Cai et al., 2018; Wang et al., 2018). In addition to the contamination of MPs in freshwater aquaculture water sources, various freshwater aquaculture patterns, such as cycled-water, cement-pool, net-cage, rice-field, and fish-light, can release MPs into aquaculture waters (Sahu et al., 2016; Lv et al., 2020). Due to the multiple sources of MPs, freshwater aquaculture objects are inevitably subjected to MP pollution. However, less is known on the effects of MPs on freshwater species, especially economic freshwater fish.

In recent years, the harm of MPs to the immune system of fish by affecting the expression of immune genes in fish has been revealed. Tumor necrosis factor- $\alpha$ (TNF- $\alpha)$, interleukin (IL), and interferon (IFN) are important factors in the immune system, which play the role of activating immune cells, regulating immune cells, and activating antiviral cells, respectively (Samuel, 2001; Whyte, 2007). Huang et al. (2020b) showed that the expressions of TNF- $\alpha$, IL-6, and IFN in the liver of the guppy Poecilia reticulata were significantly increased after 28 days of exposure to MPs. What is more, MPs not only affect the expression of IFN at the gene level but also increase the secretion of the protein corresponding to IFN (Jin et al., 2018). Luo et al. (2021) found that MPs induced the expression of increased IL8 compared with the control group. The expression changes of these proinflammatory biomarkers under the MPs make them become the important index on the evaluation of fish welfare.

Hypoxia, a common phenomenon in aquaculture, which can be caused by temperature rise, eutrophication, high-density aquaculture, and water pollution (Wang M. et al., 2021), often occurs at the bottom of the water body, leading to behavioral change (Xu et al., 2006), metabolic obstruction (Obirikorang et al., 2020), and decreased immunity (Ngoepe et al., 2020) of aquaculture objects. What is more, hypoxia can aggravate the negative effects of other environmental stressors on aquatic animals (Hu et al., 2016; Somo et al., 2020), thus reducing the production efficiency of aquaculture. With the deepening of research, the hypoxia-inducible factor (HIF) is found to be the main transcription factor regulating the hypoxia signaling pathway in vertebrates (Wang C. et al., 2020). HIF-1 is widely used in the study of hypoxia (Xu et al., 2021), and the $\alpha$ subunit of HIF-1 is most sensitive to hypoxia compared with the $\beta$ subunit (Abdel-Tawwab et al., 2019). Although this subunit has a short half-life in cells, it is difficult to be hydrolyzed under hypoxia and accumulates in large quantities in cells, which can activate the hypoxia signaling pathway (He et al., 2019). At present, the HIF-1 $\alpha$ gene sequence has been successfully cloned from an aquaculture object, and its function in the hypoxia signaling pathway has been found (Lin et al., 2021). In addition, other studies have shown that HIF- $1 \alpha$ plays an important role in regulating inflammation, but this effect has only been found in higher vertebrates such as human cells and mouse cells ( $\mathrm{Li}$ et al., 2020; Pena et al., 2020).

On the one hand, MPs are newly emerging environmental pollutants in freshwater aquaculture, which have been confirmed the biological accumulation of aquaculture species ( $\mathrm{Lv}$ et al., 2020). On the other hand, hypoxia is a traditional inhibitor of aquaculture and often occurs in an aquatic pond ( $\mathrm{Xu}$ et al., 2006). However, the effect of these two simultaneous factors at the bottom of the pond on benthic objects is unknown.

The yellow catfish Pelteobagrus fulvidraco is a unique freshwater aquaculture species in China, which is widely loved for its delicious meat. Its production reached 565,477 tons in 2020 (Fisheries Administration, Ministry of Agriculture and Rural Affairs, People's Republic of China, 2021). Hypoxia occurs frequently in yellow catfish aquaculture due to the intensive, high-density, and high-feeding farming, while MPs were also detected from yellow catfish in a reservoir (Zhang et al., 2017; Wang M. et al., 2021). However, this research on yellow catfish mainly focuses on breeding and nutrition (Wang et al., 2021b; Zhao et al., 2021), while the information on the complex effects of MPs and hypoxia on its physiology and ecology is very scarce. In contrast, compared with other freshwater aquaculture fish, their scaleless bodies make them more vulnerable to MPs and their immune function more important (Feng et al., 2019), and the demersal habits of yellow catfish make them more susceptible to MPs and hypoxia. Therefore, we aimed to study the specific growth rate (SGR) and immune-associated genes, i.e., HIF- $1 \alpha$, TNF- $\alpha$, IL- 8 , and IFN of yellow catfish under combined exposure of hypoxia and MPs. We concluded that (1) MPs cause the cellular immunological stress of yellow catfish and (2) hypoxia aggravates the negative effects of MPs on immune parameters of yellow catfish at a high concentration.

\section{MATERIALS AND METHODS Ethics Statement}

The processes involving animals complied with the Animal Research: Reporting of in vivo Experiments (ARRIVE) guidelines. All experiments were conducted under the approval of the research committee of the Institute of Hydrobiology, Chinese Academy of Sciences. 


\section{Fish}

The juvenile yellow catfish (size $5.80 \pm 0.31 \mathrm{~cm}$, body weight $3.00 \pm 0.74 \mathrm{~g}$ ) were collected from Huai'an Research Center of Hydrobiology Research Institute, Chinese Academy of Sciences. Before the experiment, 1,000 yellow catfish were acclimated for 2 weeks in indoor tanks with a circulating water filtration system. During the domestication process, water quality parameters were controlled as follows: temperature $27.2 \pm 0.4^{\circ} \mathrm{C}, \mathrm{pH} 7.1 \pm 0.62$, dissolved oxygen (DO) $6.73 \pm 0.3 \mathrm{mg} / \mathrm{L}$, and ammonia nitrogen $<0.1 \mathrm{mg} / \mathrm{L}$. All these parameters were measured by using YSI Professional Plus (Ohio, USA). The fish were fed an expanded pellet diet (1.8 g/day) containing more than $40 \%$ of protein at 08:00 and 18:00 (Qianjiang Jiajia Biotechnology Co., Ltd., Qianjiang, China) every day.

\section{Microplastics and Hypoxia}

The MPs (polystyrene, green fluorescent microsphere, $20 \mu \mathrm{m}$, density: $10 \mathrm{mg} / \mathrm{cm}^{3}$, and excitation and emission peaks: 488 and $518 \mathrm{~nm}$ ) used in the experiment were purchased from Tianjin Baseline Chromtech Research Centre, Tianjin, China. Based on Wang X. et al. (2020), before the exposure experiment, a scanning electron microscope (SEM, S-3400N, Hitachi, Japan) and a micro-Fourier transform infrared spectroscope (m-FT-IR, NICOLET iN10, Thermo Fisher Scientific, USA) were used to detect and validate the MPs used in the experiment, respectively. According to the study by Fu and Wang (2019), in the Chinese freshwater ecosystem, the most serious polluted level and the main size of MPs are 25,800 particles $/ \mathrm{m}^{3}$ and $20 \mu \mathrm{m}$, respectively. Thus, two MP concentrations, i.e., 25.8 particles/L (about $0.115 \mu \mathrm{g} / \mathrm{L}$, represented the environmental concentration) and 2,580 particles/L (about $11.5 \mu \mathrm{g} / \mathrm{L}$, represented the high concentration), as well as the control treatment (0 particles/L) were set for the experiment. A stock solution of MPs in ultrapure water was prepared and then sonicated $30 \mathrm{~min}$ before using for the experiment (Li et al., 2021).

Based on the DO in acclimation and the study by Diaz and Rosenberg (2008), the normoxia and hypoxia were set to 6.7 and $2.0 \mathrm{mg} / \mathrm{L}$, respectively. The hypoxic condition in the experimental tank was achieved through the fish respiration consumption and the adjustment of the air stone in the tank. This method has been verified in the experiment by Wang M. et al. (2021), and the DO can be reduced to $2.0 \mathrm{mg} / \mathrm{L}$ within $2 \mathrm{~h}$. In short, before the beginning of hypoxic exposure, the tank was sealed with kraft paper, and the aeration device was closed. The kraft paper was opened when the DO reached the specified value, which was detected by YSI Professional Plus, and the aeration amount of the aeration device was controlled to stabilize the DO.

\section{Exposure Experiment}

The exposure lasted for 15 days and included six groups, namely, normoxia + no-MPs, normoxia + low concentration MPs, normoxia + high concentration MPs, hypoxia + noMPs, hypoxia + low concentration MPs, and hypoxia + high concentration MPs. After the acclimation, a total of 540 healthy fish was randomly sampled and divided averagely into six experimental groups, and each group had three repeated tanks $(560 \times 350 \times 340 \mathrm{~mm}$, with $30 \mathrm{~L}$ of water, $N=30)$.
TABLE 1 | Primers for qPCR identification of HIF- $1 \alpha$, TNF, IL-8, IFN, and $\beta$-actin.

\begin{tabular}{|c|c|c|}
\hline Gene & & Primer sequence $\left(5^{\prime}-3^{\prime}\right)$ \\
\hline \multirow[t]{2}{*}{$\mathrm{HIF}-1 \alpha$} & $\mathrm{F}$ & CGGATCCAGAGCAAAGCGAT \\
\hline & $\mathrm{R}$ & TTAGCATGACGTCGTCTCCG \\
\hline \multirow[t]{2}{*}{ TNF } & $\mathrm{F}$ & ATAACCCACGCCTATGACTG \\
\hline & $\mathrm{R}$ & GGCTATGACTCGCAACACTT \\
\hline \multirow[t]{2}{*}{ IL-8 } & $\mathrm{F}$ & CACTCACCAAGCCAGCAATG \\
\hline & $\mathrm{R}$ & AGACAACCCAAGACTTCACC \\
\hline \multirow[t]{2}{*}{ IFN } & $\mathrm{F}$ & AGAGGCAAGGAGTCTGAGGTATT \\
\hline & $\mathrm{R}$ & CCAGGTGAGAGGTGACATTGTG \\
\hline \multirow[t]{2}{*}{$\beta$-actin } & $\mathrm{F}$ & TTCGCTGGAGATGATGCT \\
\hline & $\mathrm{R}$ & CGTGCTCAATGGGGTACT \\
\hline
\end{tabular}

At the beginning of the experiment, MPs were added to the relevant tanks to achieve the desired concentrations. To maintain water quality and concentrations of MPs, water in each tank was renewed for $1 \mathrm{~s}$ every day (appropriate modifications were made on the basis of Huang et al., 2020a), and then the measures mentioned above were repeated to make sure each tank meet the exposure condition. Except for DO, all water parameters during the experiment were similar to the acclimation. In addition, the survival of the fish was recorded after the renewal of the water.

\section{Sampling}

After 15 days of exposure, the weight of fish from each tank was recorded $(N=4)$. Then the gill (the major organ for breath) and liver (the major organ for detoxification) were collected from them which were anesthetized by $120 \mathrm{mg} / \mathrm{L}$ of $3-$ aminobenzoic acid ethyl ester methanesulfonate (MS-222, Cat. No. A5040, Sigma-Aldrich., Shanghai, China) and put into the liquid nitrogen to freeze quickly, and the gills and livers of four fish in each tank were mixed into one sample. All the samples were stocked in $-80^{\circ} \mathrm{C}$ refrigerator for biochemical analysis.

\section{Quantitative PCR}

The method of Trizol was used to extract the total RNA from the gills and livers, and the concentration and purity of RNA were determined by using a microspectrophotometer (Thermo Fisher Scientific, USA). The cDNA was synthesized with total RNA using the reverse transcription kit [PrimeScript $(r)$ RT Reagent Kit with gDNA Eraser] according to the instructions.

After determining the amplification efficiency of primers (>90\%, Table 1), the relative expressions of HIF-1 $\alpha$ (in gills), TNF, IL-8, and IFN (in livers) were detected by qPCR. The qPCR was conducted on the 7500 Real-Time PCR System (Applied Biosystems, USA) using the $2 \times$ SYBR Green qPCR Mix (Antibody, ROX) (Genenode Biotech Ltd., Cat\# 4302). The mixture of qPCR included $1 \mu \mathrm{l}$ of cDNA, $0.25 \mu \mathrm{l}$ of forward and reverse primers, and $5 \mu \mathrm{l}$ of $2 \times$ SYBR Green qPCR Mix (Antibody), and the RNase-free $\mathrm{ddH}_{2} \mathrm{O}$ were added to fill a total volume of $10 \mu \mathrm{l}$. After full mixing, the following qPCR procedures were executed: $95^{\circ} \mathrm{C}$ for $3 \mathrm{~min}$, followed by 40 cycles of $95^{\circ} \mathrm{C}$ for $15 \mathrm{~s}$ and $60^{\circ} \mathrm{C}$ for $30 \mathrm{~s}$. Finally, the relative expression 

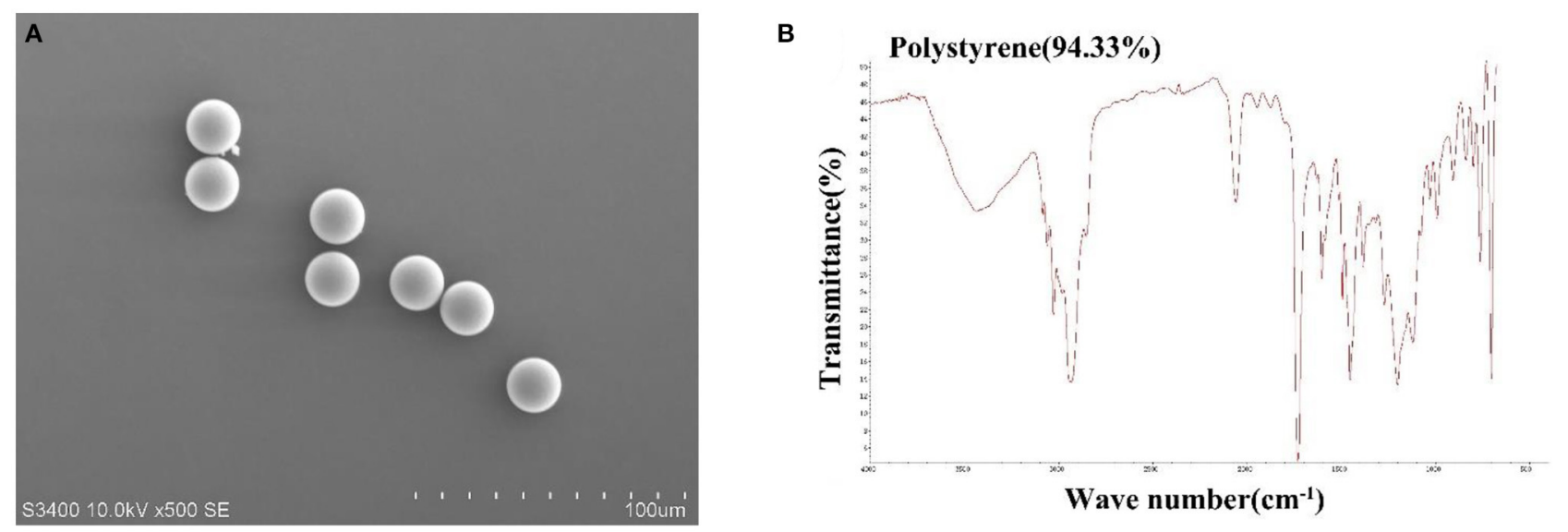

FIGURE 1 | Scanning electron microscope (SEM) image of MPs (A) and micro-Fourier transform infrared (m-FT-IR) spectroscopy of MPs (B).

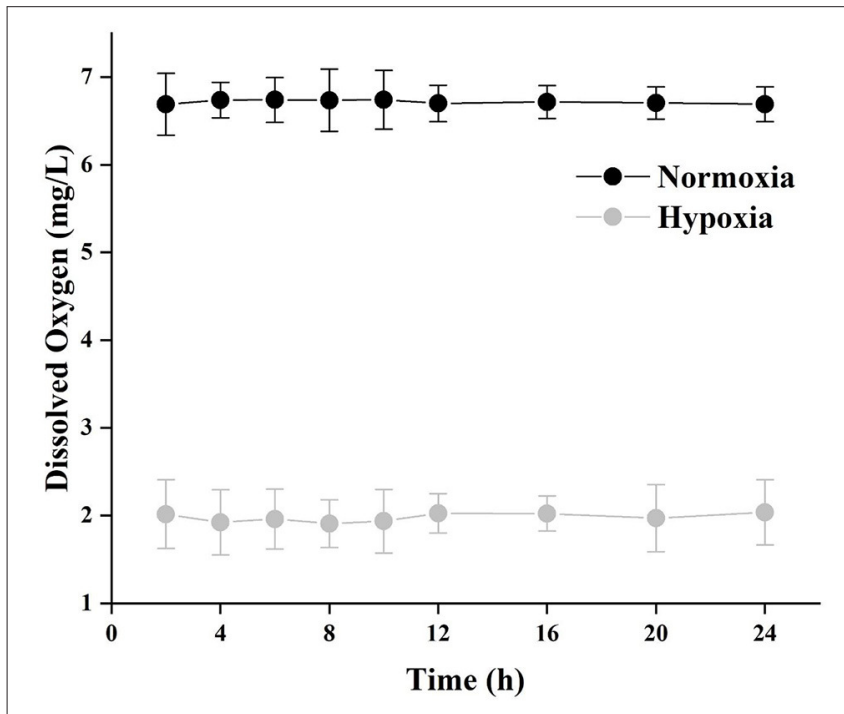

FIGURE 2 | The data of dissolved oxygen (DO) under normoxia and hypoxia after renewing the water every day $(N=15)$. The $X$-axis is the time after renewing the water, and the $Y$-axis is the DO at the corresponding time.

levels were measured by using the $2^{-\Delta \Delta \mathrm{Ct}}$ method using $\beta$-actin as an internal reference.

\section{Statistical Analysis}

The SGR was calculated by the following formula according to the study by Yang et al. (2015) by using Excel 2019:

Specific growth rate $(\mathrm{SGR}, \%)=100 \times\left[\ln \left(W_{\mathrm{t}}\right)-\ln \left(W_{0}\right)\right] / t$

where $W_{\mathrm{t}}(\mathrm{g})$ and $W_{0}(\mathrm{~g})$ are the final and initial fish body weights, respectively, and $t$ means duration.

The results were expressed as mean $\pm \mathrm{SD}$. After verifying the distribution normality of the data by using the KolmogorovSmirnov test, two-way ANOVA was used to analyze the effects of MPs, hypoxia, and their interaction. Then, the effects of MPs at each fixed DO and the effects of DO at each MP concentration were evaluated by using the one-way ANOVA and Student's $t$ test, respectively. Significance was indicated by $P<0.05$. For all biochemical parameters, the principal component analysis (PCA) was used to reduce the complexity of multiple index analyses. The Pearson coefficient $(r)$ was used to compute the correlation between variables, and only the correlations with $|r|>0.4$ and $P$ $<0.05$ were considered to perform the unary line fitting. All the analysis and data visualizations (including SGR) are conducted on the Origin Pro 2018C.

\section{RESULTS}

\section{Characteristics of MPs}

The spectrum match of MPs according to m-FT-IR was $94 \%$ (Figure 1A). The shape of MPs is smooth sphere, and the particle size is $20.2 \pm 0.04 \mu \mathrm{m}(N=5)$ according to SEM (Figure 1B).

\section{Dissolved Oxygen}

The DO for normoxia and hypoxia treatments every day is shown in Figure $2(N=15)$. Two hours after renewing the water, the DO of hypoxia groups reached $2.02 \pm 0.39 \mathrm{mg} / \mathrm{L}$ and was maintained at this level until the next water renewing. The DO of normoxia groups was $6.72 \pm 0.25 \mathrm{mg} / \mathrm{L}$.

\section{Specific Growth Rate}

No significance was observed in the interaction between MPs and DO in SGR (Table 2). Although the SGRs in hypoxia are all lower than in normoxia regardless of MP concentrations, there was no statistical difference between treatments $(P>0.05$, Figure 3$)$.

\section{The Relative Expression of HIF-1 $\alpha$}

There was no significant interactive effect of MPs and DO on HIF-1 $\alpha$ (Table 2). After 15 days of exposure, HIF- $1 \alpha$ was increased in both 0.115 and $11.5 \mu \mathrm{g} / \mathrm{L}$ MPs significantly compared with the control $(0 \mu \mathrm{g} / \mathrm{L})$ under normoxia $(P<$ 0.05). However, under hypoxia, no significant difference among the three MP treatments was observed. Compared with the normoxia, hypoxia significantly increased HIF-1 $\alpha$ when there 
TABLE 2 | Summary of two-way ANOVA results on effects of microplastics (MPs) and dissolved oxygen (DO) on SGR, HIF-1 $\alpha$, TNF- $\alpha$, IL-8, and IFN of Pelteobagrus fulvidraco.

\begin{tabular}{|c|c|c|c|c|c|c|c|c|c|c|}
\hline \multirow[t]{2}{*}{ Source } & \multirow[t]{2}{*}{ df } & \multicolumn{3}{|c|}{ HIF-1 $1 \alpha$} & \multicolumn{3}{|c|}{ TNF- $\alpha$} & \multicolumn{3}{|c|}{ IL-8 } \\
\hline & & MS & $F$ & $P$ & MS & $\boldsymbol{F}$ & $P$ & MS & $F$ & $P$ \\
\hline MPs & 2 & 1.513 & 2.326 & 0.140 & 0.655 & 34.926 & $<0.01$ & 0.341 & 8.536 & $<0.01$ \\
\hline DO & 1 & 0.027 & 0.041 & 0.842 & $<0.01$ & 0.031 & 0.863 & 0.080 & 2.009 & 0.182 \\
\hline MPs $\times D O$ & 2 & 0.617 & 0.948 & 0.415 & 0.191 & 10.182 & $<0.01$ & 0.282 & 7.057 & $<0.01$ \\
\hline Error & 12 & 0.650 & & & 0.019 & & & 0.040 & & \\
\hline \multirow[t]{2}{*}{ Source } & df & \multicolumn{3}{|c|}{ IFN } & \multicolumn{3}{|c|}{ SGR } & & & \\
\hline & & MS & $\mathbf{F}$ & $\mathbf{P}$ & MS & $\mathbf{F}$ & $\mathbf{P}$ & & & \\
\hline MPs & 2 & 1.047 & 131.158 & $<0.01$ & $<0.01$ & 0.383 & 0.690 & & & \\
\hline DO & 1 & 0.084 & 10.500 & 0.007 & 0.008 & 0.737 & 0.407 & & & \\
\hline MPs $\times D O$ & 2 & 0.599 & 75.098 & $<0.01$ & $<0.01$ & 0.04 & 0.961 & & & \\
\hline Error & 12 & 0.008 & & & 0.011 & & & & & \\
\hline
\end{tabular}

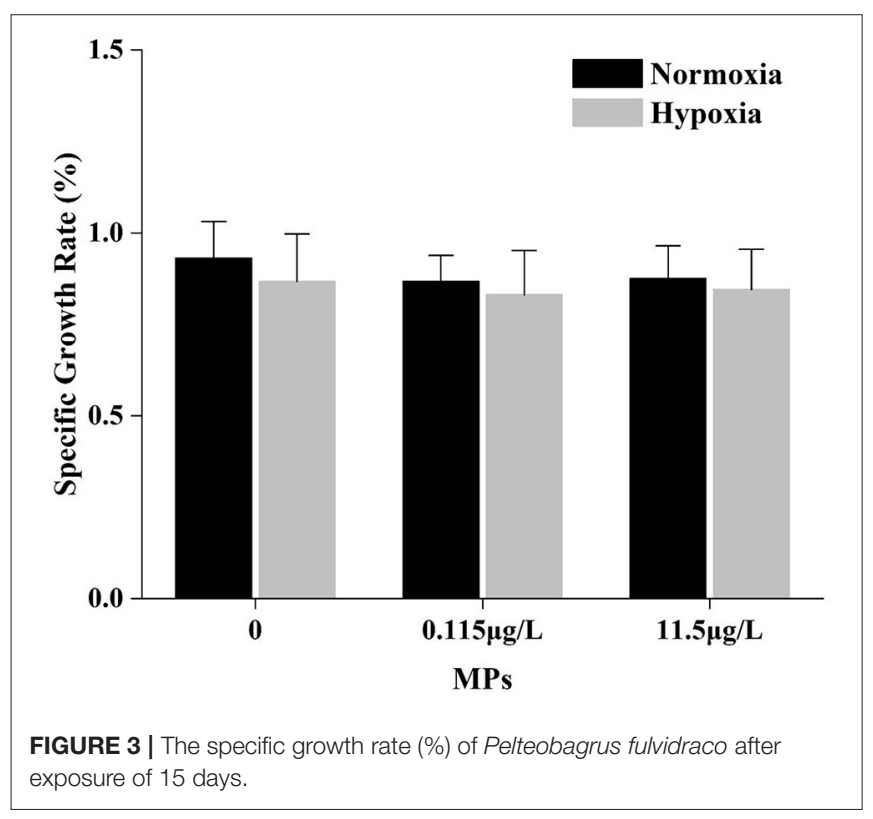

were no MPs but significantly reduced HIF-1 $\alpha$ under high MP treatment $(11.5 \mu \mathrm{g} / \mathrm{L})(P<0.05$, Figure $4 \mathrm{~A})$.

\section{The Relative Expression of TNF- $\alpha$, IL-8, and IFN}

There were significant interactions between MPs and DO on TNF- $\alpha$, IL-8, and IFN (Table 2).

In normoxia, TNF- $\alpha$ was significantly increased in 0.115 and $11.5 \mu \mathrm{g} / \mathrm{L}$ MPs compared with the control $(0 \mu \mathrm{g} / \mathrm{L}$ ) (Figure 4B, $P<0.05)$. There was no significant difference in IL-8 among three MP treatments under normoxia (Figure 4C, $P<0.05$ ). However, compared with the 0 and $0.115 \mu \mathrm{g} / \mathrm{L}$ MPs, IFN was decreased in $11.5 \mu \mathrm{g} / \mathrm{L}$ MPs under normoxia (Figure 4D, $P<$ $0.05)$. Under hypoxia, TNF and IL-8 were significantly increased and significantly decreased in $11.5 \mu \mathrm{g} / \mathrm{L}$ MPs compared with the control, respectively (Figures 4B,C, $P<0.05$ ). Surprisingly, there was a significant concentration-dependent decrease in IFN in hypoxia (Figure $4 \mathrm{D}, P<0.05$ ).

In non-MP treatment, IFN in hypoxia was higher than those in normoxia significantly (Figure $4 \mathrm{D}, P<0.05$ ). Only TNF in hypoxia was lower than that in normoxia under $0.115 \mu \mathrm{g} / \mathrm{L}$ MP treatment (Figure 4B, $P<0.05$ ). In addition, there were significantly lower expressions of IL- 8 and IFN under hypoxia than normoxia in $11.5 \mu \mathrm{g} / \mathrm{L}$ MPs (Figures 4C,D, $P<0.05$ ).

\section{PCA and Correlation Analysis}

As shown by PCA, PC1 accounted for $43.17 \%$ of all variables, which separated the presence or absence of MP treatments. PC2 accounted for $32.60 \%$ of all variables, which separated normoxia and hypoxia (Figure 5).

The Pearson coefficient $(r)$ between variables is shown in Table 3, and the $r$ between TNF and HIF- $1 \alpha$ and IL-8 and IFN was greater than 0.4 . However, only the $r$ between TNF and HIF$1 \alpha$ was considered according to the standard mentioned above $(r$ $=0.49129>0.4, P=0.0384<0.05)$. According to the scatter diagram, we chose the unary equation, the sine function, and the logarithmic function to fit the data, compared the fitting degree of the three models, and determined that the unary equation was the most suitable model (Supplementary Table S1).

Unary linear regression was the best model to fit the correlation between TNF and HIF- $1 \alpha$. The fitting equation was $y=1.23416 x+0.07637\left(r^{2}=0.24137\right)$ and all the data points was in $95 \%$ prediction bands except one (Figure 6).

\section{DISCUSSION}

Microplastics have become a hot topic since Thompson et al. (2004) discovered them. But there is still less research on MPs in freshwater organisms than in marine organisms. The QinghaiTibet Plateau is the birthplace of many rivers (e.g., the Yangtze River, the Yellow River, and the Lancang River). However, Jiang 


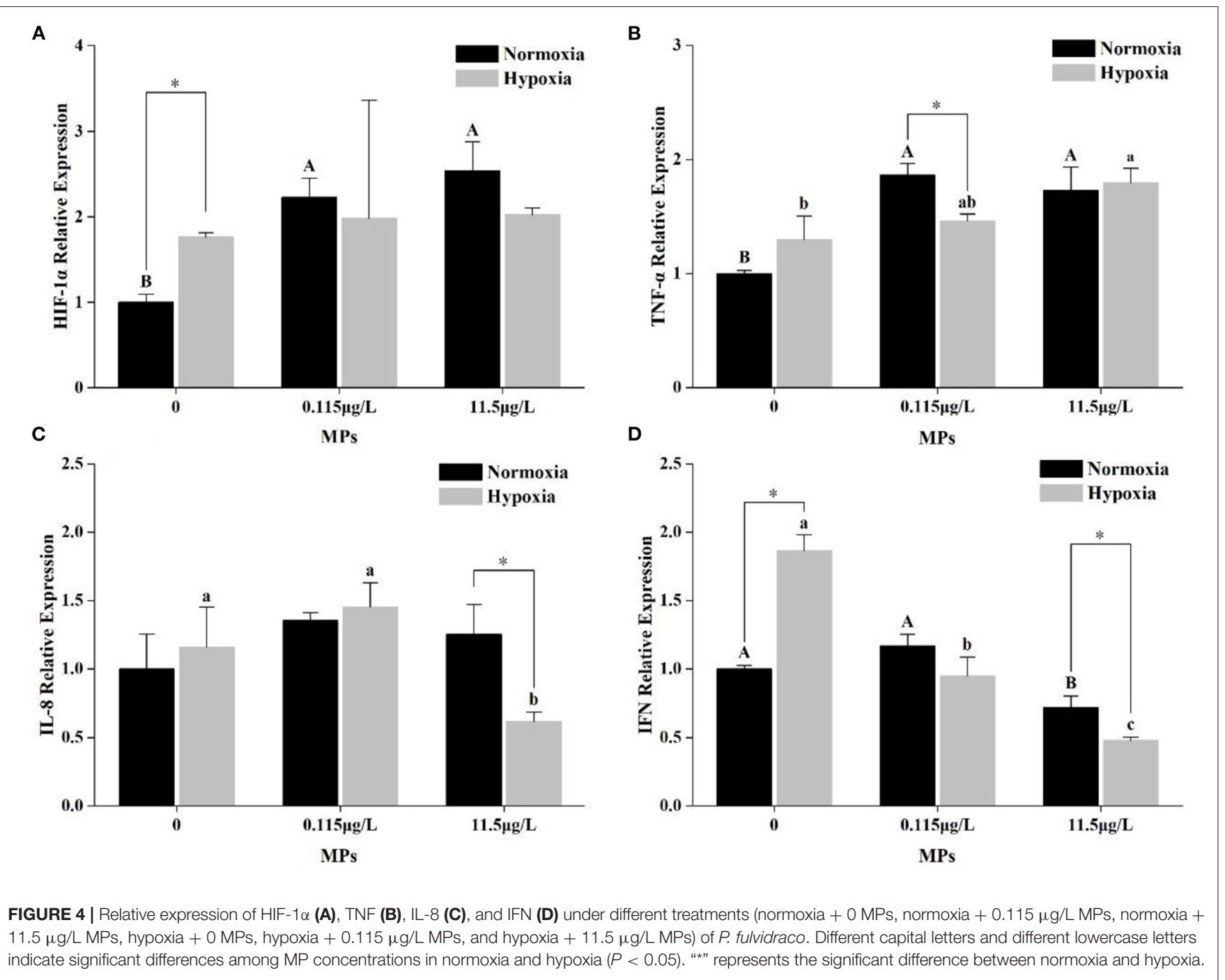

et al. (2019) found that the water bodies of the Qinghai-Tibet Plateau contained MPs, and the Yangtze River would receive more than $3.1 \times 10^{5}$ tons MPs each year (Lebreton et al., 2017). Some studies have carried out the toxicological effects of MPs on tilapia (Oreochromis niloticus), but the size of MP particles ( 0.1 and $5 \mu \mathrm{m}$, respectively) and the exposure concentration (100 and $50 \mu \mathrm{g} / \mathrm{L}$, respectively) are far from the results of the environmental investigation (Ding et al., 2018; Huang Y. et al., 2021). Based on Fu and Wang (2019), in Chinese freshwater ecosystem, the highest MP concentration is 25,800 items $/ \mathrm{m}^{3}$, and the smallest size of MPs is just about $20 \mu \mathrm{m}$. Therefore, this study can provide environmentally relevant insights on MPs in the field of freshwater based on the real size and concentration in the environment.

The SGR was an important index to measure the economic benefits of fisheries, and the larger the value was, the greater of fish would be. Malinich et al. (2018) found that MPs had no impact on the growth of the fathead minnow Pimephales promelas, and a similar result was detected from the brown trout Salmo trutta (Jakubowska et al., 2020). However, MPs could induce growth inhibition in the common carp Cyprinus carpio. The reason for the difference may be the different exposure methods (waterborne or foodborne). In this study, yellow catfish did not exhibit a significant difference between MP treatments, and it might be associated with the smooth and spherical shape of MPs, which made them easily expel from the intestine (Mazurais et al., 2015). Hypoxia could inhibit the growth of juvenile fish, which had been reported previously (Yang et al., 2013; Campbell and Rice, 2014), and yellow catfish showed a significant decrease in SGR under hypoxia for 8 weeks (Yang et al., 2015). Under hypoxia, although there was no statistical difference, a minimal lower change could be seen compared with normoxia in only 15 days of exposure, which indicated that the hypoxia may impact the growth of yellow catfish regardless of the presence or absence of MPs.

Hypoxia can increase the expression of HIF-1 $\alpha$ in organisms has been confirmed in a large number of studies (Kelly et al., 2020; Wang M. et al., 2021; Xu et al., 2021). HIF-1 is a heterodimer composed of HIF-1 $\alpha$ and HIF-1 $\beta$ (Semenza, 1998). Among them, HIF-1 $\beta$ is insensitive to the changes in $\mathrm{O}_{2}$ 


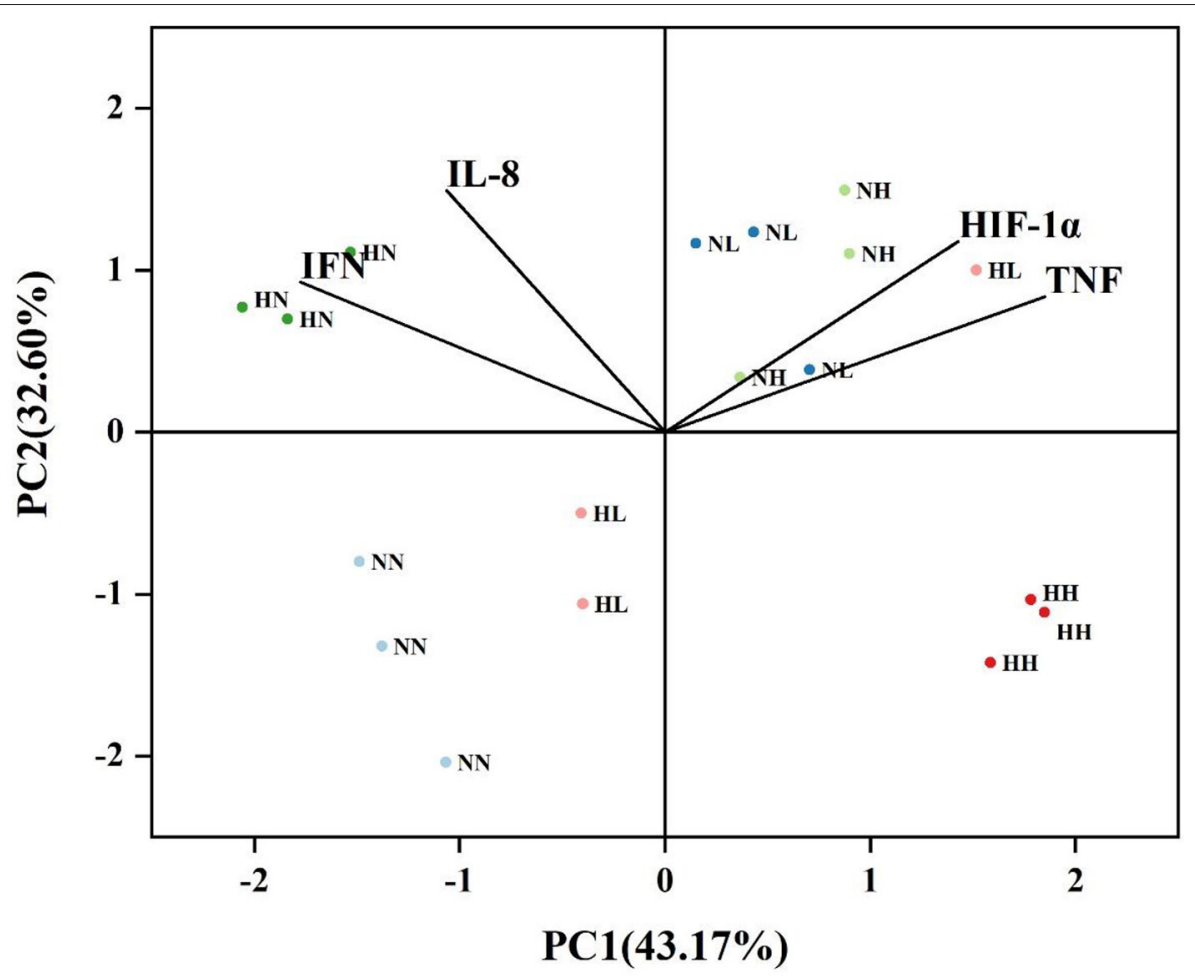

FIGURE 5 | The PCA of P. fulvidraco for 15 days of exposure (NN: normoxia + 0 MPs, NL: normoxia $+0.115 \mu \mathrm{g} / \mathrm{L}$ MPs, NH: normoxia $+11.5 \mu \mathrm{g} / \mathrm{L}$ MPs, HN: hypoxia + O MPs, HL: hypoxia + $0.115 \mu \mathrm{g} / \mathrm{L} \mathrm{MPs,} \mathrm{and} \mathrm{HH:} \mathrm{hypoxia} \mathrm{+} 11.5 \mu \mathrm{g} / \mathrm{L} \mathrm{MPs)}$.

TABLE 3 | The Pearson coefficient ( $r$ ) between HIF-1 $\alpha$, TNF, IL-8, and IFN of $P$. fulvidraco.

\begin{tabular}{llcccc}
\hline & & HIF-1 $\alpha$ & TNF & IL-8 & IFN \\
\hline HIF-1 $\alpha$ & Pearson coefficient $(r)$ & 1 & 0.49129 & 0.01644 & -0.08288 \\
& $P$ value & - & 0.0384 & 0.94839 & 0.74371 \\
\multirow{2}{*}{ TNF } & Pearson coefficient $(r)$ & 0.49129 & 1 & 0.01041 & -0.36829 \\
& P value & 0.0384 & - & 0.96729 & 0.13264 \\
\multirow{2}{*}{ IL-8 } & Pearson coefficient $(r)$ & 0.01644 & 0.01041 & 1 & 0.45988 \\
& P value & 0.94839 & 0.96729 & - & 0.05483 \\
IFN & Pearson coefficient $(r)$ & -0.08288 & -0.36829 & 0.45988 & 1 \\
& $P$ value & 0.74371 & 0.13264 & 0.05483 & - \\
\hline
\end{tabular}

availability, while HIF- $1 \alpha$ can accumulate in large quantities in vivo due to its difficulty in degradation under hypoxia, activating the hypoxia signaling pathway (Uchida et al., 2004). Activated hypoxia signaling pathways modulate other biological processes associated with increased $\mathrm{O}_{2}$ release or decreased $\mathrm{O}_{2}$ consumption, such as the regulations of erythropoietin, glucose transporter, glycolytic enzyme, and expression of vascular endothelial growth factor (Semenza, 1999), allowing the organism to adapt to new environmental changes. This could also explain why the expression of HIF- $1 \alpha$ changes significantly under hypoxia compared with normoxia. As shown in Figure 4A, both low $(0.115 \mu \mathrm{g} / \mathrm{L})$ and high $(11.5 \mu \mathrm{g} / \mathrm{L})$ concentration MPs could increase the expression of HIF-1 $\alpha$ under normoxia. A similar result was obtained in the microcrustacean Daphnia pulex (Liu Z. et al., 2020), despite nanoplastics were used in their experiments, which might be more biotoxic than MPs (Browne et al., 2008). It was possible that HIF- $1 \alpha$ could also be used as an indicator for toxicological tests of contaminants as well as other cytokines, such as the heat shock proteins (Varo et al., 2019; Jaikumar et al., 2021). Although this study did not detect the presence and quantity of MPs in gill tissues, it could be speculated from previous studies that the increased expression of HIF-1 $\alpha$ might be related to the accumulation of MPs in gill tissues, which would influence the normal respiration ( $\mathrm{Lu}$ et al., 2016; Wang et al., 2019; Huang et al., 2020a). However, in this study, we did not find that MPs increased the expression of HIF$1 \alpha$ under hypoxia treatment, indicating that MPs did not exert biological toxicity under hypoxia. As we know, fish will head out of the water to utilize the oxygen in the air when they live in the hypoxic water environment (Juca-Chagas, 2004), and this behavior is defined as "floating head." During the experiment, in the hypoxia group, "floating head" was recorded. This behavior could decrease the amount of water fish filtered, reduce the number of MPs getting into fish, and thus ease the negative effects of MPs. Oxygen was necessary for the survival of oxygenconsuming organisms, and organisms had already developed an effective defense mechanism in the face of the occasional lack of oxygen during survival (Bickler and Buck, 2007). However, in the face of emerging environmental pollutants such as MPs, yellow catfish seemingly did not find an effective solution to resist the 


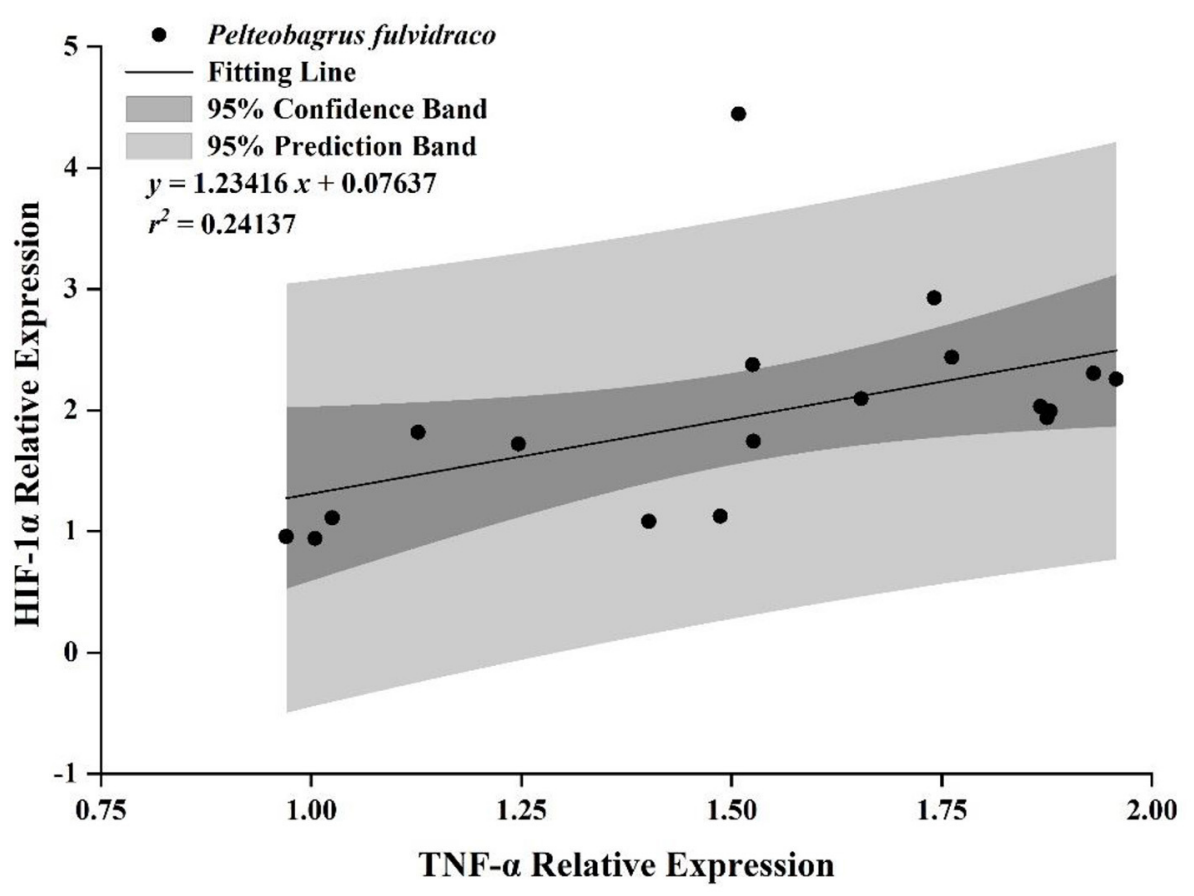

FIGURE 6 | The correlation between the relative expression of HIF-1 $\alpha$ and TNF of $P$. fulvidraco by unary linear regression.

impacts of MPs, but hypoxia can hold back the effects of MPs on HIF- $1 \alpha$.

According to previous studies, harmful substances in the environment, such as MPs, heavy metals, pesticides, and antibiotics, could cause the inflammatory response of organisms (Liu H. et al., 2020; Maselli et al., 2020; Pirsaheb et al., 2020; Wang Y. et al., 2021). However, inflammatory responses in fish were often closely related to cytokines such as TNF, IL, and IFN (Falcão et al., 2021). TNF- $\alpha$ is an important immune factor that is heavily induced in injury, inflammation, and wound responses and activates macrophages, enhancing their phagocytosis and clearance to pathogens (Secombes et al., 2001). TNF- $\alpha$ has been shown to induce the expression of other genes involved in the immune response, such as IL- $1 \beta$, IL- 8 , and COX2. IL- 8 , the first known chemokine, mainly attracts the movement of neutrophils, T-lymphocytes, and basophils in the body (Whyte, 2007). IFN is a secreted protein that induces antiviral activity in vertebrates and regulates apoptosis and cellular immunity (Samuel, 2001). Three factors interact to enhance the resistance of organisms to the external environment. Therefore, the transcription of these three types of immune factors was detected to comprehensively evaluate the immune status of yellow catfish.

In this study, the expressions of the three immune factors showed different changes under different MP concentrations. Under normoxia, the expressions of TNF- $\alpha$ were significantly increased with the presence of MPs. This suggested that MPs activated immune mechanisms in yellow catfish, which was due to the activation of the NF- $\mathrm{B}$ signaling pathway, leading to the increased expression of related signaling factors (Wu et al., 2020; Yang et al., 2020). The same result was also obtained by Luo et al. (2021) who studied zebrafish (Danio rerio). Compared with normoxia, the expression of TNF- $\alpha$ was higher under hypoxia with $0 \mathrm{MPs}$, although this increase was not significant. Martinez et al. (2020) have found that hypoxia increased the expression level of TNF- $\alpha$, and it was similar to our results. Under hypoxia, the relative expression of TNF- $\alpha$ was lower than those under normoxia in $0.115 \mu \mathrm{g} / \mathrm{L} \mathrm{MP}$ treatment. But in $11.5 \mu \mathrm{g} / \mathrm{L} \mathrm{MP}$ treatment, TNF- $\alpha$ was higher than those in $0.115 \mu \mathrm{g} / \mathrm{L} \mathrm{MPs}$ under hypoxia. It is explained that hypoxia could reduce the negative effects of MPs on yellow catfish to some extent. The reasons for this result might be the reduced uptake of MPs by fish (direct reason) and the regulation of HIF-1 $\alpha$ (indirect reason).

In contrast, the relative expression of IL- 8 in normoxia was not influenced by the MPs, and it might be due to the size of MPs. Based on the experiment in Danio rerio, $0.5 \mu \mathrm{m}$ MPs could decrease the relative expression of IL-8, but $50 \mu \mathrm{m}$ MPs did not have the same negative effects (Jin et al., 2018), and the fact that smaller MPs have more serious negative effects has been proved by Browne et al. (2008). Under hypoxia, the variation tendency of IL-8 was the same as the normoxia condition which mainly showed an increase at $0.115 \mu \mathrm{g} / \mathrm{L}$ MPs and a decrease at 11.5 $\mu \mathrm{g} / \mathrm{L}$ MPs, although the decrease at $11.5 \mu \mathrm{g} / \mathrm{L}$ was significant. In the study by Zhang et al. (2019) on the immune effects of di-2-ethylhexyl phthalate (DEHP, a kind of phthalic acid ester, PAEs) on yellow catfish P. fulvidraco, it was also observed that the relative expression of IL- 8 increased at low concentration 
DEHP and decreased at high concentration DEHP. We held the opinion that this variation tendency of IL- 8 was unique to yellow catfish exposed to environmental pollutants. However, the relative expression of IL-8 in $11.5 \mu \mathrm{g} / \mathrm{L}$ MPs in hypoxia was lower than that in normoxia, which explained that the composite effects of hypoxia and high concentration MPs could inhibit the expression of IL-8. And the interactive effects of hypoxia and MPs were observed in this study, which indicated that hypoxia aggravates the inhibition of hypoxia in the expression of IL-8. But this interaction did not have the same inhibition in $0.115 \mu \mathrm{g} / \mathrm{L}$ MPs under hypoxia, which might be related to the decrease of MP intake.

As a cytokine, IFN plays an important role in the immunity of the body, apoptosis, and antivirus (Samuel, 2001). Previous studies have shown that MPs can increase the relative expression of IFN in zebrafish (Danio rerio) and guppies (Poecilia reticulata) (Jin et al., 2018; Huang et al., 2020b). In this study, we also saw an increase in the relative expression of IFN in $0.115 \mu \mathrm{g} / \mathrm{L}$ MP treatment under normoxia, although this increase was not significant. It might be related to the inflammatory response caused by MPs. However, in the $11.5 \mu \mathrm{g} / \mathrm{L} \mathrm{MP}$ group, the expression of IFN was significantly reduced under normoxia, which had not been found before. As mentioned above, it might be related to the difference of the species. Previous studies have shown that hypoxia could cause a significant increase in the expression of IFN (Niklasson et al., 2011; Chen et al., 2017), and the same result was obtained in this study. Based on the result of two-way ANOVA, a significant interaction of hypoxia and MPs was observed. This concentration-dependent interaction induced the inhibition in the expression of IFN.

According to the PCA, two principal components accounted for $75.77 \%$ of the total composition. PC1 separated MP treatment from non-MP treatment, accounting for 43.17 of the total variances, while PC2 separated normoxic treatment from hypoxic treatment, accounting for $32.60 \%$ of the total variances, indicating that MP treatment had a greater impact on yellow catfish. Significant positive correlation between TNF- $\alpha$ and HIF- $1 \alpha$, and this relationship had been discovered in mouse cells and human cells (van Uden et al., 2008; Li et al., 2020). We also found that there was a relationship between TNF- $\alpha$ and HIF- $1 \alpha$ in fish, which could make up the gap between HIF- $1 \alpha$ and TNF- $\alpha$ in fish. When inflammation occurred in the body, TNF- $\alpha$ induced a large number of macrophages to accumulate in the inflammatory site, consumed a large amount of oxygen, resulting in hypoxia in the inflammatory part and the production of a large number of HIF- $1 \alpha$ (Cummins et al., 2016). In contrast, TNF- $\alpha$ could activate the NF- $\kappa \mathrm{B}$ signaling pathway to produce $\mathrm{NF}-\kappa \mathrm{B}$ factor, and several subsequent NF- $\kappa \mathrm{B}$ subunits bind to the promoter of HIF- $1 \alpha$, thereby inducing HIF- $1 \alpha$ production in the body (Lin and Simon, 2016; Warbrick and Rabkin, 2019). In addition, HIF- $1 \alpha$ plays a crucial role in the initiation, regulation, and coordination of cell responses during inflammation (Frede et al., 2007).

\section{CONCLUSION}

This study filled the gap in understanding the effects of MPs on benthic fish under hypoxia. In this study, MPs were able to induce immune responses on yellow catfish. Hypoxia seemed to alleviate the effects of MPs at $0.115 \mu \mathrm{g} / \mathrm{L}$ on yellow catfish to some extent, but the interaction between hypoxia and MPs aggravated the negative effects of MPs on the expression of immune parameters on yellow catfish at $11.5 \mu \mathrm{g} / \mathrm{L}$ MPs. Thus, attention should be paid to the harm of MPs to aquaculture fish species, and the occurrence of hypoxia in water bodies should be reduced as far as possible. To form a systematic understanding, future studies should focus on the molecular pathway of immune cells in fish exposed to MPs and hypoxia.

\section{DATA AVAILABILITY STATEMENT}

The original contributions presented in the study are included in the article/Supplementary Material, further inquiries can be directed to the corresponding author/s.

\section{ETHICS STATEMENT}

The animal study was reviewed and approved by Animal Research: Reporting of In Vivo Experiments (ARRIVE) guidelines Institute of Hydrobiology, Chinese Academy of Sciences.

\section{AUTHOR CONTRIBUTIONS}

LL: formal analysis, investigation, methodology, data curation, writing-original draft, and review and editing. RX: formal analysis, investigation, methodology, visualization, and writingreview and editing. LJ: investigation and methodology. EX and $\mathrm{MH}$ : investigation and writing-review and editing. MW, JW, and BL: investigation and methodology. LZ: funding acquisition, supervision, validation, and writing-review and editing. YW: conceptualization, supervision, validation, and writing-review and editing. All authors contributed to the article and approved the submitted version.

\section{FUNDING}

This study was supported by the China Agriculture Research System of MOF and MARA (CARS-46) and the Subei Science and Technology Project of Jiangsu Province (Grant Nos.: SZ-HA2019017 and SZ-HAJH202005).

\section{SUPPLEMENTARY MATERIAL}

The Supplementary Material for this article can be found online at: https://www.frontiersin.org/articles/10.3389/fphys. 2021.753999/full\#supplementary-material 


\section{REFERENCES}

Abdel-Tawwab, M., Monier, M. N., Hoseinifar, S. H., and Faggio, C. (2019). Fish response to hypoxia stress: growth, physiological, and immunological biomarkers. Fish Physiol. Biochem. 45, 997-1013. doi: 10.1007/s10695-019-00614-9

Bickler, P. E., and Buck, L. T. (2007). Hypoxia tolerance in reptiles, amphibians, and fishes: life with variable oxygen availability. Annu. Rev. Physiol. 69, 145-170. doi: 10.1146/annurev.physiol.69.031905.162529

Browne, M. A., Dissanayake, A., Galloway, T. S., Lowe, D. M., and Thompson, R. C. (2008). Ingested microscopic plastic translocates to the circulatory system of the mussel, Mytilus edulis (L.). Environ. Sci. Technol. 42, 5026-5031. doi: $10.1021 /$ es800249a

Cai, M., He, H., Liu, M., Li, S., Tang, G., Wang, W., et al. (2018). Lost but can't be neglected: huge quantities of small microplastics hide in the South China Sea. Sci. Total Environ. 633, 1206-1216. doi: 10.1016/j.scitotenv.2018.03.197

Campbell, L. A., and Rice, J. A. (2014). Effects of hypoxia-induced habitat compression on growth of juvenile fish in the Neuse River Estuary, North Carolina, USA. Mar. Ecol. Prog. Ser. 497, 199-213. doi: 10.3354/meps10607

Chen, N., Wu, M., Tang, G. P., Wang, H. J., Huang, C. X., Wu, X. J., et al. (2017). Effects of Acute Hypoxia and Reoxygenation on Physiological and Immune Responses and Redox Balance of Wuchang Bream (Megalobrama amblycephala Yih, 1955). Front. Physiol. 8:375. doi: 10.3389/fphys.2017.00375

Cole, M., Lindeque, P., Halsband, C., and Galloway, T. S. (2011). Microplastics as contaminants in the marine environment: a review. Mar. Pollut. Bull. 62, 2588-2597. doi: 10.1016/j.marpolbul.2011.09.025

Cummins, E. P., Keogh, C. E., Crean, D., and Taylor, C. T. (2016). The role of HIF in immunity and inflammation. Mol. Aspects Med. 47-48, 24-34. doi: 10.1016/j.mam.2015.12.004

Diaz, R. J., and Rosenberg, R. (2008). Spreading dead zones and consequences for marine ecosystems. Science 321, 926-929. doi: 10.1126/science.1156401

Ding, J., Zhang, S., Razanajatovo, R. M., Zou, H., and Zhu, W. (2018). Accumulation, tissue distribution, and biochemical effects of polystyrene microplastics in the freshwater fish red tilapia (Oreochromis niloticus). Environ. Pollut. 238, 1-9. doi: 10.1016/j.envpol.2018.03.001

Falcão, M. A. P., Dantas, M. C. da S., Rios, C. T., Borges, L. P., Serafini, M. R. and Walker, C. I. (2021). Zebrafish as a tool for studying inflammation: a systematic review. Rev. Fish Sci. Aquac. 2021, 1-31. doi: 10.1080/23308249.2021.1898538

Feng, Z., Zhang, T., Li, Y., He, X., Wang, R., Xu, J., et al. (2019). The accumulation of microplastics in fish from an important fish farm and mariculture area, Haizhou Bay, China. Sci. Total Environ. 696:133948. doi: 10.1016/j.scitotenv.2019.133948

Fisheries Administration Ministry of Agriculture and Rural Affairs, People's Republic of China. (2021). China Fisheries Statistical Yearbook 2021. Beijing: Chinese Agriculture Express Beijing.

Frede, S., Berchner-Pfannschmidt, U., and Fandrey, J. (2007). "Regulation of hypoxia-inducible factors during inflammation," in Oxygen Biology and Hypoxia, 403-419. doi: 10.1016/S0076-6879(07)35021-0

$\mathrm{Fu}, \mathrm{Z}$., and Wang, J. (2019). Current practices and future perspectives of microplastic pollution in freshwater ecosystems in China. Sci. Total Environ. 691, 697-712. doi: 10.1016/j.scitotenv.2019.07.167

Gu, H., Wei, S., Hu, M., Wei, H., Wang, X., Shang, Y., et al. (2020). Microplastics aggravate the adverse effects of BDE-47 on physiological and defense performance in mussels. J. Hazard. Mater. 398:122909. doi: 10.1016/j.jhazmat.2020.122909

Hamidian, A. H., Ozumchelouei, E. J., Feizi, F., Wu, C., Zhang, Y., and Yang, M. (2021). A review on the characteristics of microplastics in wastewater treatment plants: a source for toxic chemicals. J. Clean. Prod. 295:126480. doi: 10.1016/j.jclepro.2021.126480

He, J., Yu, Y., Qin, X. W., Zeng, R. Y., Wang, Y. Y., Li, Z. M., et al. (2019). Identification and functional analysis of the Mandarin fish (Siniperca chuatsi) hypoxia-inducible factor-1alpha involved in the immune response. Fish Shellfish Immunol. 92, 141-150. doi: 10.1016/j.fsi.2019.04.298

Hu, M., Wu, F., Yuan, M., Liu, Q., and Wang, Y. (2016). Combined effects of toxic cyanobacteria Microcystis aeruginosa and hypoxia on the physiological responses of triangle sail mussel Hyriopsis cumingii. J. Hazard. Mater. 306, 24-33. doi: 10.1016/j.jhazmat.2015.11.052
Huang, J. N., Wen, B., Meng, L. J., Li, X. X., Wang, M. H., Gao, J. Z., et al. (2020a). Integrated response of growth, antioxidant defense and isotopic composition to microplastics in juvenile guppy (Poecilia reticulata). J. Hazard. Mater. 399:123044. doi: 10.1016/j.jhazmat.2020.123044

Huang, J. N., Wen, B., Zhu, J. G., Zhang, Y. S., Gao, J. Z., and Chen, Z. Z. (2020b). Exposure to microplastics impairs digestive performance, stimulates immune response and induces microbiota dysbiosis in the gut of juvenile guppy (Poecilia reticulata). Sci. Total Environ. 733:138929. doi: 10.1016/j.scitotenv.2020.138929

Huang, W., Wang, X., Chen, D., Xu, E. G., Luo, X., Zeng, J., et al. (2021). Toxicity mechanisms of polystyrene microplastics in marine mussels revealed by high-coverage quantitative metabolomics using chemical isotope labeling liquid chromatography mass spectrometry. J. Hazard. Mater. 417:126003. doi: $10.1016 /$ j.jhazmat.2021.126003

Huang, Y., Ding, J., Zhang, G., Liu, S., Zou, H., Wang, Z., et al. (2021). Interactive effects of microplastics and selected pharmaceuticals on red tilapia: role of microplastic aging. Sci. Total Environ. 752:142256. doi: 10.1016/j.scitotenv.2020.142256

Jaikumar, I. M., Periyakali, S. B., Rajendran, U., Joen-Rong, S., Thanasekaran, J., and Tsorng-Harn, F. (2021). Effects of microplastics, polystyrene, and polyethylene on antioxidants, metabolic enzymes, HSP-70, and myostatin expressions in the giant river prawn Macrobrachium rosenbergii: impact on survival and growth. Arch. Environ. Contam. Toxicol. 80, 645-658. doi: 10.1007/s00244-021-00833-3

Jakubowska, M., Bialowas, M., Stankeviciute, M., Chomiczewska, A., Pazusiene, J., Jonko-Sobus, K., et al. (2020). Effects of chronic exposure to microplastics of different polymer types on early life stages of sea trout Salmo trutta. Sci. Total Environ. 740:139922. doi: 10.1016/j.scitotenv.2020.139922

Jiang, C., Yin, L., Li, Z., Wen, X., Luo, X., Hu, S., et al. (2019). Microplastic pollution in the rivers of the Tibet Plateau. Environ. Pollut. 249, 91-98. doi: 10.1016/j.envpol.2019.03.022

Jin, Y., Xia, J., Pan, Z., Yang, J., Wang, W., and Fu, Z. (2018). Polystyrene microplastics induce microbiota dysbiosis and inflammation in the gut of adult zebrafish. Environ. Pollut. 235, 322-329. doi: 10.1016/j.envpol.2017.12.088

Juca-Chagas, R. (2004). Air breathing of the neotropical fishes Lepidosiren paradoxa, Hoplerythrinus unitaeniatus and Hoplosternum littorale during aquatic hypoxia. Comp. Biochem. Physiol. Part A Mol. Integr. Physiol. 139, 49-53. doi: 10.1016/j.cbpb.2004.06.019

Kelly, T., Johnsen, H., Burgerhout, E., Tveiten, H., Thesslund, T., Andersen, O., et al. (2020). Low oxygen stress during early development influences regulation of hypoxia-response genes in farmed Atlantic Salmon (Salmo salar). G3 (Bethesda) 10, 3179-3188. doi: 10.1534/g3.120.401459

Lebreton, L. C. M., van der Zwet, J., Damsteeg, J. W., Slat, B., Andrady, A., and Reisser, J. (2017). River plastic emissions to the world's oceans. Nat. Commun. 8:15611. doi: 10.1038/ncomms15611

Li, L., Gu, H., Chang, X., Huang, W., Sokolova, I. M., Wei, S., et al. (2021). Oxidative stress induced by nanoplastics in the liver of juvenile large yellow croaker Larimichthys crocea. Mar. Pollut. Bull. 170:112661. doi: 10.1016/j.marpolbul.2021.112661

Li, L. F., Liu, Y. Y., Lin, S. W., Chang, C. H., Chen, N. H., Hung, C. Y., et al. (2020). Low-molecular-weight heparin reduces ventilation-induced lung injury through hypoxia inducible factor-1alpha in a murine endotoxemia model. Int. J. Mol. Sci. 21:3097. doi: 10.3390/ijms21093097

Lin, N., and Simon, M. C. (2016). Hypoxia-inducible factors: key regulators of myeloid cells during inflammation. J. Clin. Invest. 126, 3661-3671. doi: 10.1172/JCI84426

Lin, Y., Miao, L. H., Liu, B., Xi, B. W., Pan, L. K., and Ge, X. P. (2021). Molecular cloning and functional characterization of the hypoxia-inducible factor-1alpha in bighead carp (Aristichthys nobilis). Fish Physiol. Biochem. 47, 351-364. doi: 10.1007/s10695-020-00917-2

Liu, H., Fu, S., Zhang, S., Ding, M., and Wang, A. (2020). Lead induces structural damage, microbiota dysbiosis and cell apoptosis in the intestine of juvenile bighead carp (Hypophthalmichthys nobilis). Aquaculture 528:735573. doi: 10.1016/j.aquaculture.2020.735573

Liu, Z., Huang, Y., Jiao, Y., Chen, Q., Wu, D., Yu, P., et al. (2020). Polystyrene nanoplastic induces ROS production and affects the MAPK-HIF-1/NFkBmediated antioxidant system in Daphnia pulex. Aquat. Toxicol. 220:105420. doi: 10.1016/j.aquatox.2020.105420 
Lu, Y., Zhang, Y., Deng, Y., Jiang, W., Zhao, Y., Geng, J., et al. (2016). Uptake and accumulation of polystyrene microplastics in Zebrafish (Danio rerio) and toxic effects in liver. Environ. Sci. Technol. 50, 4054-4060. doi: 10.1021/acs.est.6b00183

Luo, T., Weng, Y., Huang, Z., Zhao, Y., and Jin, Y. (2021). Combined hepatotoxicity of imidacloprid and microplastics in adult zebrafish: endpoints at gene transcription. Comp. Biochem. Physiol. C. Toxicol. Pharmacol. 246:109043. doi: 10.1016/j.cbpc.2021.109043

Lv, W., Yuan, Q., He, D., Lv, W., and Zhou, W. (2020). Microplastic contamination caused by different rearing modes of Asian swamp eel (Monopterus albus). Aquac. Res. 51, 5084-5095. doi: 10.1111/are.14847

Malinich, T. D., Chou, N., Sepulveda, M. S., and Hook, T. O. (2018). No evidence of microplastic impacts on consumption or growth of larval Pimephales promelas. Environ. Toxicol. Chem. 37, 2912-2918. doi: 10.1002/etc.4257

Martinez, D., De Lazaro, O., Cortes, P., Oyarzun-Salazar, R., Paschke, K., and Vargas-Chacoff, L. (2020). Hypoxia modulates the transcriptional immunological response in Oncorhynchus kisutch. Fish Shellfish Immunol. 106, 1042-1051. doi: 10.1016/j.fsi.2020.09.025

Maselli, K. M., Gee, K., Isani, M., Fode, A., Schall, K. A., and Grikscheit, T. C. (2020). Broad-spectrum antibiotics alter the microbiome, increase intestinal fxr, and decrease hepatic steatosis in zebrafish short bowel syndrome. Am. J. Physiol. Gastrointest. Liver Physiol. 319, G212-G226. doi: 10.1152/ajpgi.00119.2020

Mazurais, D., Ernande, B., Quazuguel, P., Severe, A., Huelvan, C., Madec, L., et al. (2015). Evaluation of the impact of polyethylene microbeads ingestion in European sea bass (Dicentrarchus labrax) larvae. Mar. Environ. Res. 112, 78-85. doi: 10.1016/j.marenvres.2015.09.009

Ngoepe, T. K., Qiang, J., Chen, D., Tao, Y., f., Bao, J., et al. (2020). The effects of dissolved oxygen and dietary protein levels on growth performance, physiological parameters and the immune response of the genetically improved farmed tilapia juveniles (Oreochromis niloticus). Aquac. Res. 52, 547-558. doi: $10.1111 /$ are. 14913

Niklasson, L., Sundh, H., Fridell, F., Taranger, G. L., and Sundell, K. (2011). Disturbance of the intestinal mucosal immune system of farmed Atlantic salmon (Salmo salar), in response to long-term hypoxic conditions. Fish Shellfish Immunol. 31, 1072-1080. doi: 10.1016/j.fsi.2011.09.011

Obirikorang, K. A., Acheampong, J. N., Duodu, C. P., and Skov, P. V. (2020). Growth, metabolism and respiration in Nile tilapia (Oreochromis niloticus) exposed to chronic or periodic hypoxia. Comp. Biochem. Physiol. Part A Mol. Integr. Physiol. 248:110768. doi: 10.1016/j.cbpa.2020.110768

Pena, E., Brito, J., El Alam, S., and Siques, P. (2020). Oxidative stress, kinase activity and inflammatory implications in right ventricular hypertrophy and heart failure under hypobaric hypoxia. Int. J. Mol. Sci. 21:6421. doi: 10.3390/ijms21176421

Pirsaheb, M., Hossini, H., and Makhdoumi, P. (2020). Review of microplastic occurrence and toxicological effects in marine environment: experimental evidence of inflammation. Process Saf. Environ. Prot. 142, 1-14. doi: 10.1016/j.psep.2020.05.050

Sahu, A., Yadav, N., and Sudhakar, K. (2016). Floating photovoltaic power plant: a review. Renew. Sust. Energ. Rev. 66, 815-824. doi: 10.1016/j.rser.2016. 08.051

Samuel, C. E. (2001). Antiviral actions of interferons. Clin. Microbiol. Rev. 14, 778-809, table of contents. doi: 10.1128/CMR.14.4.778-809.2001

Secombes, C. J., Wang, T., Hong, S., Peddie, S., Crampe, M., Laing, K. J., et al. (2001). Cytokines and innate immunity of fish. Dev. Comp. Immunol. 25, 713-723. doi: 10.1016/S0145-305X(01)00032-5

Semenza, G. L. (1998). Hypoxia-inducible factor 1: master regulator of O2 homeostasis. Curr Opin in Genet Dev 8, 588-594. doi: 10.1016/S0959-437X(98)80016-6

Semenza, G. L. (1999). Regulation of mammalian $\mathrm{O}_{2}$ homeostasis by hypoxia-inducible factor 1. Annu. Rev. Cell Dev. Biol. 15, 551-578. doi: 10.1146/annurev.cellbio.15.1.551

Shang, X., Lu, J., Feng, C., Ying, Y., He, Y., Fang, S., et al. (2020). Microplastic (1 and $5 \mu \mathrm{m}$ ) exposure disturbs lifespan and intestine function in the nematode Caenorhabditis elegans. Sci. Total Environ. 705:135837. doi: 10.1016/j.scitotenv.2019.135837

Somo, D. A., Onukwufor, J. O., Wood, C. M., and Richards, J. G. (2020). Interactive effects of temperature and hypoxia on diffusive water flux and oxygen uptake rate in the tidepool sculpin, Oligocottus maculosus. Comp. Biochem. Physiol, Part A Mol. Integr. Physiol. 250:110781. doi: 10.1016/j.cbpa.2020.110781

Su, L., Xue, Y., Li, L., Yang, D., Kolandhasamy, P., Li, D., et al. (2016). Microplastics in Taihu Lake, China. Environ. Pollut. 216, 711-719. doi: 10.1016/j.envpol.2016.06.036

Su, S., Tang, Y., Chang, B., Zhu, W., and Chen, Y. (2020). Evolution of marine fisheries management in China from 1949 to 2019: How did China get here and where does China go next? Fish Fish. 21, 435-452. doi: 10.1111/faf.12439

Thompson, R. C., Olsen, Y., Mitchell, R. P., Davis, A., Rowland, S. J., John, A. W., et al. (2004). Lost at sea: where is all the plastic? Science 304:838. doi: $10.1126 /$ science.1094559

Uchida, T., Rossignol, F., Matthay, M. A., Mounier, R., Couette, S., Clottes, E., et al. (2004). Prolonged hypoxia differentially regulates hypoxia-inducible factor (HIF)-1alpha and HIF-2alpha expression in lung epithelial cells: implication of natural antisense HIF-1alpha. J. Biol. Chem. 279, 14871-14878. doi: $10.1074 /$ jbc.M400461200

van Uden, P., Kenneth, N. S., and Rocha, S. (2008). Regulation of hypoxiainducible factor-1alpha by NF-kappaB. Biochem. J. 412, 477-484. doi: 10.1042/BJ20080476

Varo, I., Perini, A., Torreblanca, A., Garcia, Y., Bergami, E., Vannuccini, M. L., et al. (2019). Time-dependent effects of polystyrene nanoparticles in brine shrimp Artemia franciscana at physiological, biochemical and molecular levels. Sci. Total Environ. 675, 570-580. doi: 10.1016/j.scitotenv.2019.04.157

Wang, C., Wu, X., Hu, X., Jiang, H., Chen, L., and Xu, Q. (2020a). Hypoxiainducible factor lalpha from a high-altitude fish enhances cytoprotection and elevates nitric oxide production in hypoxic environment. Fish Physiol. Biochem. 46, 39-49. doi: 10.1007/s10695-019-00694-7

Wang, J., Li, Y., Lu, L., Zheng, M., Zhang, X., Tian, H., et al. (2019). Polystyrene microplastics cause tissue damages, sex-specific reproductive disruption and transgenerational effects in marine medaka (Oryzias melastigma). Environ. Pollut. 254:113024. doi: 10.1016/j.envpol.2019.113024

Wang, T., Hu, M., Xu, G., Shi, H., Leung, J. Y. S., and Wang, Y. (2021a). Microplastic accumulation via trophic transfer: Can a predatory crab counter the adverse effects of microplastics by body defence? Sci. Total Environ. 754:142099. doi: 10.1016/j.scitotenv.2020.142099

Wang, T., Li, Z., Yu, Z.-X., Wang, Z.-W., Lian, Z.-Q., Du, W.-X., et al. (2021b). Production of YY males through self-fertilization of an occasional hermaphrodite in Lanzhou catfish (Silurus lanzhouensis). Aquaculture 539:736622. doi: 10.1016/j.aquaculture.2021.736622

Wang, T., Zou, X., Li, B., Yao, Y., Li, J., Hui, H., et al. (2018). Microplastics in a wind farm area: A case study at the Rudong Offshore Wind Farm, Yellow Sea, China. Mar. Pollut. Bull. 128, 466-474. doi: 10.1016/j.marpolbul.2018.01.050

Wang, X., Huang, W., Wei, S., Shang, Y., Gu, H., Wu, F., et al. (2020). Microplastics impair digestive performance but show less effects on antioxidant activity in mussels under low pH conditions. Environ. Pollut. 258:113691. doi: 10.1016/j.envpol.2019.113691

Wang, Y., Zhao, H., Liu, Y., Li, J., Nie, X., Huang, P., et al. (2021). Environmentally relevant concentration of sulfamethoxazole-induced oxidative stress-cascaded damages in the intestine of grass carp and the therapeutic application of exogenous lycopene. Environ. Pollut. 274:116597. doi: 10.1016/j.envpol.2021.116597

Wang, M., Wu, F., Xie, S., and Zhang, L. (2021). Acute hypoxia and reoxygenation: effect on oxidative stress and hypoxia signal transduction in the juvenile yellow catfish (Pelteobagrus fulvidraco). Aquaculture 531:735903. doi: 10.1016/j.aquaculture.2020.735903

Warbrick, I., and Rabkin, S. W. (2019). Hypoxia-inducible factor 1-alpha (HIF1alpha) as a factor mediating the relationship between obesity and heart failure with preserved ejection fraction. Obes. Rev. 20,701-712. doi: 10.1111/obr.12828

Whyte, S. K. (2007). The innate immune response of finfish-a review of current knowledge. Fish Shellfish Immunol. 23, 1127-1151. doi: 10.1016/j.fsi.2007.06.005

Wu, S., Wu, M., Tian, D., Qiu, L., and Li, T. (2020). Effects of polystyrene microbeads on cytotoxicity and transcriptomic profiles in human Caco- 2 cells. Environ. Toxicol. 35, 495-506. doi: 10.1002/tox.22885

Xu, J., Liu, Y., Cui, S., and Miao, X. (2006). Behavioral responses of tilapia (Oreochromis niloticus) to acute fluctuations in dissolved oxygen levels as monitored by computer vision. Aquacult Eng 35, 207-217. doi: 10.1016/j.aquaeng.2006.02.004 
Xu, Y., Miao, Z., Li, X., Lin, H., Cheng, Y., Pan, J., et al. (2021). Hypoxiareoxygenation stress modulates the hepatopancreas transcriptome of Chinese mitten crab Eriocheir sinensis. Gene 771:145361. doi: 10.1016/j.gene.2020.145361

Yang, H., Cao, Z. D., and Fu, S. J. (2013). The effects of diel-cycling hypoxia acclimation on the hypoxia tolerance, swimming capacity and growth performance of southern catfish (Silurus meridionalis). Comp. Biochem. Physiol. Part A Mol. Integr. Physiol. 165, 131-138. doi: 10.1016/j.cbpa.2013.02.028

Yang, H., Lai, H., Huang, J., Sun, L., Mennigen, J. A., Wang, Q., et al. (2020). Polystyrene microplastics decrease F-53B bioaccumulation but induce inflammatory stress in larval zebrafish. Chemosphere 255:127040. doi: 10.1016/j.chemosphere.2020.127040

Yang, K., Fan, Q., Zhang, L., Li, B., Gao, Y., Zeng, K., et al. (2015). Effect of dissolved oxygen levels on growth performance, energy budget and antioxidant responses of yellow catfish, Pelteobagrus fulvidraco (Richardson). Aquac. Res. 46, 2025-2033. doi: 10.1111/are.12359

Zhang, K., Xiong, X., Hu, H., Wu, C., Bi, Y., Wu, Y., et al. (2017). Occurrence and characteristics of microplastic pollution in Xiangxi Bay of Three Gorges Reservoir, China. Environ. Sci. Technol. 51, 3794-3801. doi: 10.1021/acs.est.7b00369

Zhang, M., Yuan, L., Li, M., and Wang, R. (2019). Effect of acute di-2-ethylhexyl phthalate (DEHP) exposure on gene expression involved in inflammatory response in juvenile yellow catfish (Pelteobagrus fulvidraco). J. Biol. 36, 51-54. doi: 10.3969/j.issn.2095-1736.2019.06.051 (in Chinese).
Zhao, H., Peng, K., Wang, G., Mo, W., Huang, Y., and Cao, J. (2021). Metabolic changes, antioxidant status, immune response and resistance to ammonia stress in juvenile yellow catfish (Pelteobagrus fulvidraco) fed diet supplemented with sodium butyrate. Aquaculture 536:736441. doi: 10.1016/j.aquaculture.2021.736441

Conflict of Interest: The authors declare that the research was conducted in the absence of any commercial or financial relationships that could be construed as a potential conflict of interest.

Publisher's Note: All claims expressed in this article are solely those of the authors and do not necessarily represent those of their affiliated organizations, or those of the publisher, the editors and the reviewers. Any product that may be evaluated in this article, or claim that may be made by its manufacturer, is not guaranteed or endorsed by the publisher.

Copyright (c) $2021 \mathrm{Li}, \mathrm{Xu}$, Jiang, Xu, Wang, Wang, Li, Hu, Zhang and Wang. This is an open-access article distributed under the terms of the Creative Commons Attribution License (CC BY). The use, distribution or reproduction in other forums is permitted, provided the original author(s) and the copyright owner $(s)$ are credited and that the original publication in this journal is cited, in accordance with accepted academic practice. No use, distribution or reproduction is permitted which does not comply with these terms. 